\title{
МИКРОЭЛЕМЕНТНЫЙ ПРОФИЛЬ ТВЁРДЫХ ТКАНЕЙ ЗУБА И КОСТНОЙ ТКАНИ ЧЕЛЮСТЕЙ У ПАЦИЕНТОВ С ПСИХИАТРИЧЕСКОЙ ПАТОЛОГИЕЙ
}

\section{TRACE ELEMENTS OF HARD TISSUE OF TEETH AND BONE OF JAW IN PSYCHIATRIC PATIENTS}

\author{
R. Ilyina \\ L. Muhamedzhanova \\ L. Nikitina
}

Summary. Research result of trace elements in bone and hard tissue of teeth don't revealed any statistically changes in psychiatric patients of both sexes aged 35-50 years compared to the control group. In psychiatric patients aged 51-65 years was discover decrease content of calcium, copper, zinc and increase of strontium, compared to the control group. This changes can indicated about metabolic disorder of trace elements in body, it insufficient food supply, which causes the structure to change of bone by the increase of age, it decrease resistant by microflora of oral cavity, and it lead to early loss of teeth in psychiatric patients.

Keywords: trace elements, bone, hard tissue of teeth, psychiatric patients, calcium, copper, zinc, strontium.

\begin{abstract}
Ильина Роза Юрьевна
\end{abstract}
К.м.н., дочент, Казанская государственная медицинская академия — филиал ФГБОУ ДПО РМАНПО

Минздрава России ilroza@yandex.ru

Мухамеджанова Любовь Рустемовна Д.м.н., профессор, ФГБОУВО «Чувашский государственный университет им. И. Н. Ульянова» Министерства науки и высшего образования России Ir71@bk.ru

Никитина Луиза Ивановна

К.м.н., ФГБОУВО «Чувашский государственный университет им. И. Н. Ульянова» Министерства науки и высшего образования России zab@mail.ru

Аннотация. В результате исследования содержания микроэлементов в костной и твердой ткани зуба, не было выявлено достоверных изменений в группе психически больных обоего пола в возрасте 35-50 лет, по сравнению с контрольной группой. В группе 51-65 лет у пациентов с психиатрической патологией было выявлено низкое содержания кальция, меди и цинка, а также увеличение содержания стронция, по сравнению с группой контроля. Данные изменения могут свидетельствовать 0 нарушении обмена микроэлементов в организме, недостаточном поступлении их с пищей, что приводит к изменению структуры костной ткани при увеличении возраста, уменьшению ее сопротивляемости к микрофлоре полости рта, что приводит к ранней потере зубов у пациентов психиатрического профиля.

Ключевые слова: микроэлементы, костная ткань, твердые ткани зуба, психически больные, кальций, медь, цинк, стронций.
B настоящее время в мире насчитывается более 450 миллионов человек, страдающих шизофренией. В многочисленных исследованиях было установлено достоверно большее количество удаленных и пролеченных зубов у пациентов с психиатрической патологией, по сравнению с психически здоровыми людьми $[8,13]$. В исследованиях Kisely S. (2015) в результате проведенного мета-анализа 25 рандомизированных исследований была выявлена связь между длительностью госпитализации и индексом КПУ (суммой зубов с кариесом, пломбированных и удаленных) [10]. Причинами быстрой потери зубов у психически больных называли: неудовлетворительную гигиену полости рта, побочные эффекты психотропных препаратов (в том числе связан- ные с влиянием на метаболические процессы в костной ткани), а также алиментарный дефицит витаминов и микроэлементов [6]. При этом известно, что выраженная степень алиментарного дефицита эссенциальных веществ (кальция, йода, фтора и т.д.) может быть ассоциирована со структурными нарушениями в костной ткани и твердых тканей зуба. В отечественных и зарубежных литературных источниках мы обнаружили только исследование Заплаховой Н.Ф. (1974 г.) которое свидетельствует о лабильности изменений содержания цинка и меди: концентрация данных элементов зависела от стадии психиатрического заболевания и длительности процесса. В целом, у психически больных выявлено увеличение концентрации в крови меди, цинка и нике- 
ля, уменьшение свинца и марганца [3]. Мы полагаем, что оценка микроэлементного статуса позволит изучить механизмы влияния дефицита либо профицита макрои микроэлементов на отдельные звенья патогенеза структурных изменений в костной ткани, и, возможно, выявить причину быстрой потери зубов у психически больных.

\section{Цель исслеАования}

Оценка микроэлементного статуса костной и твердых тканей зуба у психически больных в зависимости от пола и возраста пациентов.

\section{Материалы и методы исследования}

В Республиканской клинической психиатрической больнице им. В.М. Бехтерева были обследованы 96 пациентов (43 мужчины и 53 женщины) в возрасте от 39 до 65 лет (51,22 7,19 года, Ме - 50,2 года) со стажем госпитализации более 5 лет. Из них 75\% (72 чел.) проходили лечение по поводу параноидной шизофрении, у остальных пациентов были диагностированы: органическое поражение головного мозга сосудистого генеза (12,5\%; 14 чел.), хронический алкоголизм (6,25\%; 6 чел.), эпилепсия с изменением личности (4,2\%; 4 чел.). Группу контроля составили 109 пациентов (56 мужчин и 53 женщины) клиники «Твой стоматолог» (г. Казань), которым проводилась экстракция зубов по санационным показаниям. Средний возраст пациентов группы контроля

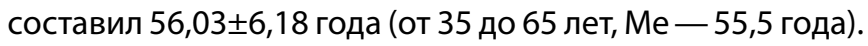

Так как микроэлементный состав костной ткани подвержен возрастным изменениям [1], группа пациентов с психиатрическим заболеванием и группа контроля были ранжированы по возрасту на две подгруппы: 1-яот 35 до 50 лет, 2-я - от 51 до 65 лет. Кроме того, после 65 лет возможно проявление клинических манифестных признаков сенильного остеопороза, что вносит вклад в содержание базовых микроэлементов в костной ткани.

Образцы костной ткани в группе сравнения и у психически больных получали в процессе экстракции зубов (для коррекции краёв лунки зуба скусывали межкорневые и/или межальвеолярные перегородки). Полученные образцы костной ткани представлены трабекулярной костью с сохранившимися фрагментами кортикальной пластинки альвеолы. Экстракция зубов проводилась по санационным показаниям (по поводу обострения хронического периодонтита, хронического генерализованного пародонтита). Содержание микроэлементов в костной ткани и твёрдых тканях зуба определялось методом атомно-абсорбционной спектрофотометрии на приборе СА10 МП в лаборатории Академии наук Республики Татарстан.
Статистический анализ полученных результатов проводили при помощи программы «SPSS-14 for Windows». Проверка выборки на нормальность распределения проводилась по критерию Колмогорова-Смирнова, выборка принята нормальной с р>0,05. Вычислялась средняя арифметическая - М, стандартное отклонение - $\mathrm{m}$. Достоверность полученных данных оценивали с помощью критерия Стьюдента с поправкой Бонферрони на множественность сравнения (С. Гланц, 1999).

\section{Результаты исслеАований}

При оценке микроэлементного статуса костной ткани и твердых тканей зубов в возрастном диапазоне 3550 лет было выявлено достоверное снижение уровней кальция, цинка и меди у больных с психиатрической патологией и увеличение содержания стронция, по сравнению с группой сравнения (таб. 1).

В данной возрастной группе пациентов практически не было достоверных различий с группой контроля. Этот факт свидетельствует об относительной компенсации воспалительно-деструктивных процессов в костной ткани пародонта и микроэлементной насыщенности твердых тканей зуба и кости. Отметим, что абсолютные значения кальция, меди и цинка снизились. Выявленное нами содержание уровня кальция в твёрдых тканях зубов и костей может быть доказательным фактом снижения минеральной плотности костной ткани у пациентов с психиатрической патологией вследствие развития системного остеопороза [14]. Обращает на себя внимание снижение содержания кальция у женщин в костной ткани по сравнению с мужчинами в группе пациентов психиатрического стационара (таб. 1). Полученные данные можно объяснить отягощенностью пациентов женского пола постменопаузальным остеопорозом, когда активно начинается вымывание кальция из костной ткани на фоне снижения выработки эстрогена [12]. Также в этой группе отмечается достоверное повышение значения стронция в зубах у мужчин и женщин.

Кальций является макроэлементом, составляющим вместе с фосфором основу кристаллической решетки костной ткани; распространенность его в организме человека очень высокая - 1,2 кг (2\% от веса тела) [2]. В возрастной группе пациентов от 51-65 лет психиатрического стационара отмечается значительное снижение содержания кальция и в костях и твёрдых тканях зуба. Снижение содержания кальция в костной ткани челюстей может свидетельствовать о наличии трабекулярного, субкортикального и кортикального остеопороза (а также различных его сочетаний), что объясняется длительным течением хронического воспалительного процесса в пародонте. Дефицит кальция в твёрдых тканях зуба (эмали и дентине) свидетельствует о недостаточной 
минерализации и обозначает степень риска инициации и прогрессирования кариозного процесса в твердых тканях зуба.

Медь, цинк и стронций относятся к микроэлементам, без участия которых невозможно функционирование многих обменных процессов в организме. Дефицит данных микроэлементов вызывает замедление роста костной ткани в детском возрасте и ускоряет потерю костной массы в пожилом возрасте [11]. Снижение содержания меди и цинка в статистически значимом диапазоне отмечается в группах мужчин и женщин с психиатрической патологией в возрастном диапазоне 51-65 лет, по сравнению с группой контроля. Дефицит меди в костной ткани влечёт за собой дефектный синтез коллагена, сопровождающийся ломкостью костей и деформацией скелета [15]. При этом в костной ткани повышается содержание растворимых фракций коллагена, нарушается процесс его продукции и созревания. Этот факт имеет существенное значение, поскольку образующийся в условиях дефицита меди и цинка коллаген достаточно быстро подвергается резорбции, поддерживая воспалительный процесс и усугубляя степень потери пародонтального прикрепления. Медь - один из важнейших и незаменимых микроэлементов в организме человека. 90\% всей меди концентрируется в мышцах и костях. В сутки взрослый человек должен получать не менее 2-5 мг меди с пищей. При уменьшении дозы менее 2 мг могут развиться медь-дефицитные состояния. Одно из известных проявлений дефицита меди - это дефектный синтез коллагена, сопровождающийся ломкостью костей и деформацией скелета у экспериментальных животных. При этом повышается количество растворимого коллагена (тропоколлагена), т.е. нарушается образование коллагена 1 типа [2,9].

Известно, что цинк стимулирует активность остеобластов костной ткани, вследствие чего возрастает содержание костного изофермента щелочной фосфатазы (ЩФ) в сыворотке крови. Цинк также тормозит активность остеокластов, предотвращая тем самым резорбцию кости. Уровень цинка могут снижать продукты распада тканей, образующихся при деструкции, например, при выраженных экссудативных явлениях в пародонтальных карманах [4]. На дефицит цинка в костной ткани альвеолы зуба может оказывать влияние деминерализованный цемент корня и грануляционная ткань. Последняя «отнимает» ионы цинка и меди из трабекулярной и кортикальной кости альвеолы для ферментативного обеспечения синтеза коллагена Наибольшее содержание цинка в организме сконцентрировано в поперечно-полосатых мышцах - там содержится 62\% всего цинка. При дефиците цинка описано угнетение щелочной фосфатазы в хондроцитах эпифизарного хряща. Цинк обеспечивает обратимость денатурации молекулы ДНК, образуя проч- ные связи с фосфатными группами, а также оказывает влияние на деление клеток путем воздействия на цитоскелет. Участие цинка в функционировании генетического аппарата и процессах деления клетки, определяет его важное значение в организме человека [7].

Воспалительно-деструктивный процесс в костной ткани может быть причиной повышения содержания стронция у больных с психиатрической патологией. Так, у пациентов обоего пола в возрастной группе 51-65 лет определяется достоверное увеличение содержания стронция в костной и зубной ткани по сравнению с группой контроля. Наиболее частой причиной воспаления в околокорневой зоне кости является хронический пародонтит. Отметим, что хронический пародонтит практически 100\%- распространенная патология полости рта у психически больных. По данным литературы, стронций входит в структуру апатита высокоминерализованных тканей организма. Высокие его концентрации угнетают процесс оссификации костной ткани. Апатитовые кристаллы, составляющие основу губчатой кости, имеют тропность к ионам кальция. Но стронций, имея ту же структуру иона, заменяет ион кальция в кристаллической решетке. Образовавшийся кристалл гидроксиапатита со стронцием является более устойчивым к костной резорбции, на этом эффекте основано лечение постменопаузального остеопороза [5].

\section{Выво $\triangle$}

В группе пациентов обоего пола в возрасте 35-50 лет у психически больных не было выявлено достоверных изменений в содержании микроэлементов в костной ткани и твердых тканях зуба. В возрастной группе 5165 лет у пациентов с психиатрической патологией было выявлено низкое содержания макроэлемента кальция, микроэлементов меди и цинка, а также увеличение содержания стронция, по сравнению с группой контроля. Данные изменения могут свидетельствовать о нарушении обмена микроэлементов в организме, недостаточном поступлении их с пищей, что приводит к истончению трабекулярных структур костной ткани, уменьшению ее сопротивляемости действию пародонтопатогенной микрофлоры полости рта. Возможно, доказанные изменения в макро- и микроэлементном составе костной ткани челюстей и твёрдых тканей зуба способствуют высокой распространенности воспалительных заболеваний пародонта и кариеса у психически больных, что, в итоге, приводит к ранней потере зубов и приобретенной (вторичной) адентии. Кроме того, полученные в ходе исследования результаты обозначают необходимость включения в комплекс реабилитационных программ для пародонтологических пациентов дифференцированных доз макро- и микроэлементов для стимуляции трабекулогенеза на всех его этапах. 


\section{ЛИТЕРАТУРА}

1. Авцын А. П., Жаворонков А. А., Риш М. А. Микроэлементозы человека// Москва. Медицина. 1991. С. 126-129.

2. Герк С. А., Голованова 0. А. Элементный состав костной ткани человека в норме и патологии//Вестник Омского университета. 2015. № 4. С. 39-44.

3. Заплахова Н. Ф. Обмен некоторых микроэлементов при шизофрении: автореф. дис. . . . канд. мед. наук. Москва, 1974. 24 с.

4. Мухамеджанова Л. Р., Хуснуллин Н. М. Рентгеноспектральный анализ костной ткани в клинической стоматологии // Успехи современного естествознания. 2004. № 4. С. 116-117.

5. Рожинская Л. Я., Беляева А. В., Белая Ж. Е. Ранелат стронция (Бивалос) — препарат двойного действия на костную ткань: новые подходы к лечению остеопороза//0стеопороз и остеопатии. 2016. № 1. С. 34-42.

6. Ashour AA, Basha S, Enan ET, Basalem A, Qahatani AA. Association between obesity/overweight and dental caries in psychiatric patients //Ann Saudi Med. 2019. № 39 (3).P.178-184.

7. Calhoun NR, Smith JC Jr, Becker KL. The role of zinc in bone metabolism// Clin Orthop Relat Res. 1974. № (103). P.212-34.

8. Đorđević V, Jovanović M, Miličić B, Stefanović V, Đukić-Dejanović S. Prevalence of dental caries in hospitalized patients with schizophrenia //Vojnosanit Pregl. 2016. № 73 (12). P.1102-8.

9. Gaffney-Stomberg E. The Impact of Trace Minerals on Bone Metabolism//Biol Trace Elem Res. 2019. № 188 (1). P.26-34.

10. Kisely S, Baghaie H, Lalloo R, Siskind D, Johnson NW. A systematic review and meta-analysis of the association between poor oral health and severe mental illness// Psychosom Med. 2015. № 77 (1). P.83-92.

11. Martusevich AK, Karuzin KA. Cohort study of microelement status in “healthy” population of Russian megapolis// Biomedicine (Taipei). 2019 . № 9 (3). P.15.

12. Okano T. Effects of essential trace elements on bone turnover — in relation to the osteoporosis // Nippon Rinsho. 1998. № 54. P. 148-154.

13. Ranjan R, Rout M, Mishra M, Kore SA. Tooth loss and dementia: An oro-neural connection. A cross-sectional study//J Indian Soc Periodontol. 2019. № 23 (2).P.158162.

14. Saltman PD, Strause LG. The role of trace minerals in osteoporosis//J Am Coll Nutr. 1993. № 12. P.384-9.

15. Zofkova I, Nemcikova P, Matucha P Trace elements and bone health// Clin Chem Lab Med. 2013. № 51 (8). P.1555-1561.

( ) Ильина Роза Юрьевна ( ilroza@yandex.ru ),

Мухамеджанова Любовь Рустемовна ( lr71@bk.ru ), Никитина Луиза Ивановна ( zab@mail.ru ).

Журнал «Современная наука: актуальные проблемы теории и практики»

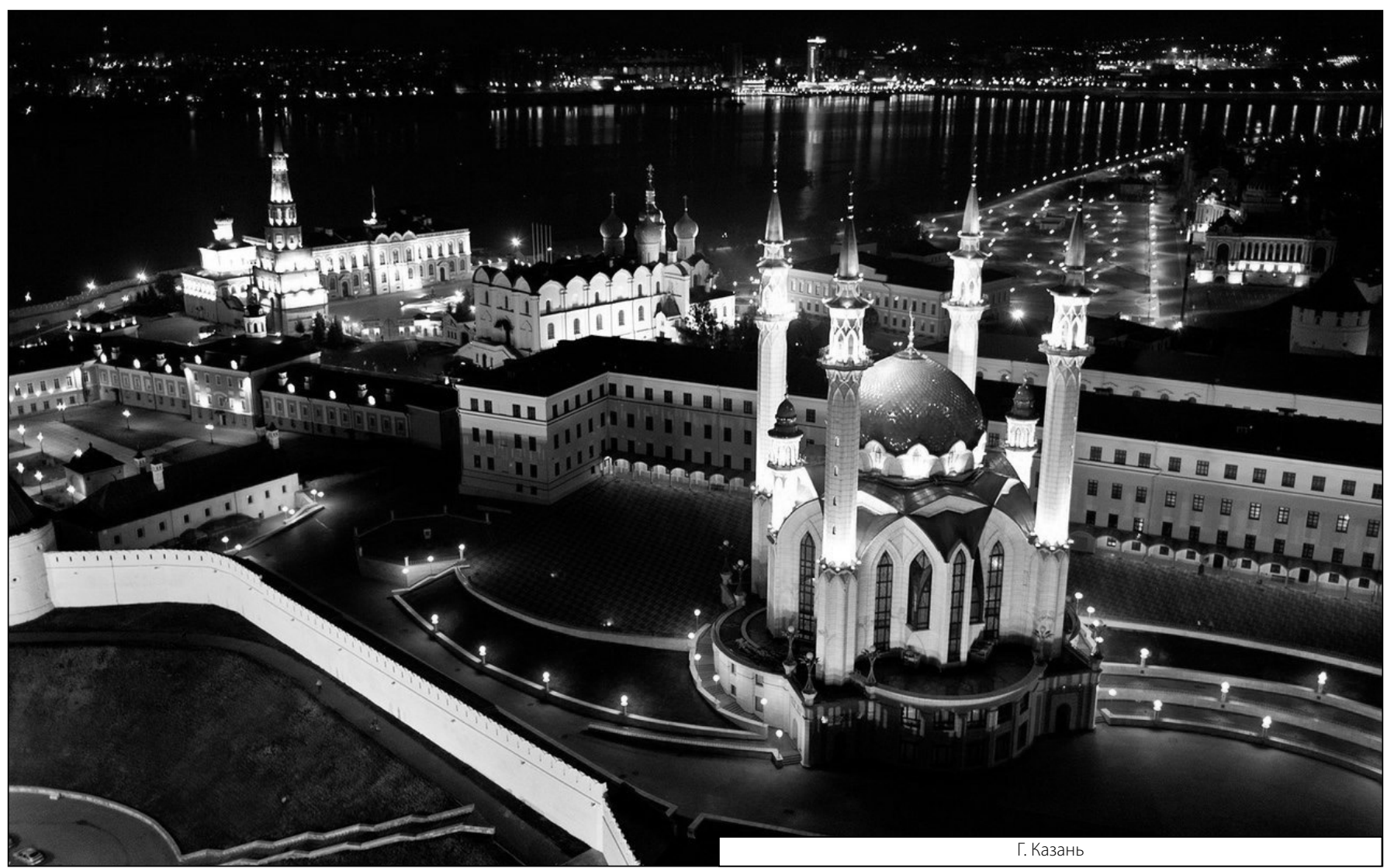

